\title{
Grupos de enfrentamento do desgaste mental no trabalho bancário: discutindo saúde mental do trabalhador no sindicato
}

\author{
Bank workers with mental strain: discussing mental health \\ in a workers' union
}

\author{
1 Professora assistente mestre do curso \\ de Psicologia da Pontifícia Universida- \\ de Católica de São Paulo (PUC-SP), São \\ Paulo, Brasil. \\ Contato: \\ Renata Paparelli \\ Endereço: Rua Monte Alegre, 984, sala \\ T-52 - Perdizes, São Paulo-SP \\ E-mail: \\ rpaparel@uol.com.br
}

Recebido: 03/11/2010

Revisado: 06/04/2011

Aprovado: 19/04/2011

\section{Resumo}

Este relato de experiência apresenta uma proposta desenvolvida por uma parceria entre o Curso de Psicologia da Pontifícia Universidade Católica de São Paulo (PUC-SP) e o Sindicato dos Bancários de São Paulo, Osasco e Região, desde 2008, no campo da saúde mental relacionada ao trabalho. Esta ação que tem se revelado promissora tanto para os trabalhadores diretamente envolvidos, quanto para o sindicato: os grupos de enfrentamento do desgaste mental no trabalho bancário. Os grupos têm como objetivos principais: desenvolver atividade de acolhimento das pessoas com desgaste mental que procuram o sindicato; compreender o processo de adoecimento no interior das trajetórias de vida e trabalho dos participantes, considerando o momento atual de reestruturação produtiva no setor bancário; contribuir com a construção de ações individuais e coletivas de enfrentamento. O resultado da experiência evidencia a potencialidade de um trabalho como esse quanto à possibilidade de compreensão do processo de adoecimento, bem como quanto à identificação de fatores de desgaste mental na categoria bancária. Além disso, os demais objetivos foram alcançados, intensificando a presença da discussão sobre saúde mental e trabalho no cotidiano do sindicato.

Palavras-chave: saúde mental e trabalho; grupos de trabalhadores; desgaste mental; sindicatos.

\begin{abstract}
This report presents the experience developed by the Course of Psychology of the Pontifícia Universidade Católica de São Paulo (PUC-SP) in a partnership with the Union of Bank Workers of São Paulo, Osasco and Region since 2008, in the field of mental health related to work: support groups for those who suffer from mental strain while working in a bank. The initiative has been beneficial for the workers, as well as for their union. The support group main purposes are: to develop activities aiming at supporting mentally strained bank workers who seek help at the union; to understand the process of illness within participant's work and life course, considering the productive reengineering banks are currently going through; and to contribute to the development of individual and collective actions to confront strain. These results evidenced the potentiality of such group activities for understanding the process of illness, as well as to identify mental strain factors among bank workers. Furthermore, our objectives were achieved, increasing the discussion about mental health and work within the workers' union routine.
\end{abstract}

Keywords: mental health and work; groups of workers; mental strain; workers' union. 


\section{Introdução}

Sabemos que os transtornos mentais relacionados ao trabalho têm se destacado por sua alta incidência em diversas categorias profissionais, tais como a dos bancários (JACQUES; AMAZARRAY, 2006; LIMA, 2000; BRESCIANI, 1999; SEGNINI, 1999), a dos trabalhadores em teletrabalho (RAMALHO et al., 2008; VILELA; ASSUNÇÃO, 2004; LUCCA; CAMPOS, 2010; JACKSON FILHO; ASSUNÇÃO, 2006), a dos professores (NEVES, 1999; PAPARELLI, 2009), entre outras. Essa constataÇão é duramente vivida no cotidiano de sindicatos, que, muitas vezes, não sabem ao certo como proceder diante do volume grande de pessoas que os procuram com esse tipo de questão. Buscando responder a esses problemas colocados pelos sindicatos e, ao mesmo tempo, aproximar os estudantes da temática da saúde da classe trabalhadora, foi firmado um convênio entre o curso de Psicologia da Faculdade de Ciências Humanas e da Saúde da PUC-SP e o Sindicato dos Bancários de São Paulo, Osasco e Região, em voga desde o ano de $2008^{2}$. Como a universidade pode colaborar com o sindicato no enfrentamento dos graves problemas de saúde mental que acometem a categoria bancária? Como dar maior visibilidade a essas questões de saúde mental relacionadas ao trabalho (SMRT) para a discussão com o movimento de trabalhadores? Construímos coletivamente (sindicato e universidade ${ }^{3}$ uma proposta que tem se revelado promissora para responder a essas inquietações: o grupo de enfrentamento do desgaste mental do trabalho bancário.

Nesse relato de experiência, apresentaremos o trabalho desenvolvido no sindicato desde 2008 e discutiremos os principais resultados obtidos até o presente momento. Para contextualizá-lo no campo das práticas grupais em Saúde do Trabalhador, teceremos considerações sobre a presença desses grupos como dispositivos de pesquisa e intervenção e sobre sua implementação em sindicatos.

\section{a) Os grupos como dispositivo de pesquisa e interven- ção em Saúde do Trabalhador}

O campo da Saúde do Trabalhador emerge como um discurso contra-hegemônico no contexto do ressurgimento do movimento sindical no Brasil, no final dos anos 1970 (LACAZ, 2007). Uma de suas características essenciais é a participação dos trabalhadores como protagonistas das ações de pesquisa e intervenção, o que faz da formação de grupos de discussão com trabalhadores uma estratégia muito utilizada. A propósito disso, Sato et al. (2003) referem-se à influên- cia do modelo operário italiano (ODDONE et al., 1986), que afirma a importância do conhecimento prático dos que trabalham no entendimento dos agravos à saúde relacionados ao trabalho:

Trata-se de experiência desenvolvida na década de 1960, junto a entidades sindicais italianas, que apresenta os trabalhadores do grupo primário (aqueles diretamente envolvidos nas atividades operativas) como protagonistas principais na definição dos problemas de saúde no trabalho. Considera-se que a avaliação das condições de trabalho e de saúde deve partir da subjetividade e do conhecimento operário. (p. 284)

Sato, Lacaz e Bernardo (2006), ao delinearem as atividades desenvolvidas pela Psicologia na área da Saúde do Trabalhador no interior da Saúde Pública, referem-se ao grupo de qualidade de vida, desenvolvido por profissionais do Programa de Saúde do Trabalhador da Zona Norte da cidade de São Paulo, no início dos anos 1990 (SATO et al., 1993; MAENO; CARMO, 2005). Essa atividade consistia na realização de encontros em grupo com trabalhadores portadores de LER/ DORT, visando à melhoria da sua qualidade de vida. Nesses encontros, era possível construir um conhecimento a respeito dos agravos pautado pela articulação entre o conhecimento teórico dos técnicos em saúde e o conhecimento prático dos trabalhadores acerca de seu trabalho e dos fatores de desgaste nele presentes. Refletindo sobre as condições de trabalho que provocaram o adoecimento, buscava-se que os participantes re-significassem seu trabalho e o processo de adoecimento ocorrido em seu interior. Atualmente, a modalidade de atendimento em grupo é adotada por muitos Centros de Referência em Saúde do Trabalhador (Cerests) com ênfases diferentes conforme cada instituição (caráter formativo-terapêutico, psicoterapêutico, ênfase no resgate da cidadania e formação de laços de solidariedade entre os pares etc.).

Outras atividades em que os grupos de trabalhadores são considerados estratégicos são as ações de vigilância em Saúde do Trabalhador, nas quais a discussão entre os pares viabiliza o acesso ao conhecimento sobre a organização do trabalho, sem o qual a avaliação das condições de trabalho e do processo saúde-doença não é possível (SATO, 1996).

Por fim, os grupos de discussão com trabalhadores estão muito presentes em pesquisas em Saúde do Trabalhador, nas quais são analisados os fatores de desgaste de determinada categoria profissional (NEVES, 1999), o sofrimento psicológico de pessoas que vivem a situação de desemprego (FARINA; NEVES, 2007), os sintomas de determinados agravos à saúde (CHIESA et al., 2002) etc.

\footnotetext{
${ }^{2}$ Esse mesmo tipo de convênio foi estabelecido, em 2010, com o Sindicato dos Professores de São Paulo (Sinpro) - professores da rede particular de ensino.

${ }^{3}$ Nesse processo, destaca-se a participação de Walcir Previtale Bruno, secretário de saúde do Sindicato dos Bancários de São Paulo, Osasco e Região, de Maria Maeno, médica sanitarista, e Antonio Arruda Rebouças, advogado especializado em Previdência Social, ambos com trajetória de trabalho junto ao movimento sindical e particularmente à categoria bancária.
} 
b) Ações em saúde mental relacionada ao trabalho em sindicatos: notas sobre um encontro

Realizamos um levantamento bibliográfico preliminar em periódicos buscando artigos que relatassem práticas de enfrentamento do desgaste mental realizadas por profissionais da saúde mental em sindicatos e encontramos apenas um relato de pesquisa que investigou essa questão. Trata-se de investigação desenvolvida por Sales e Sanches (2009), em que analisam a presença de psicólogos em sindicatos em Belo Horizonte-MG e verificam que, das quinze entidades contatadas, apenas duas contavam com o trabalho desses profissionais (são eles: representantes de trabalhadores do setor de telecomunicações e do ramo metalúrgico). As entrevistas realizadas pelos pesquisadores com os dirigentes sindicais dessas duas entidades revelam que um dos principais motivos para a presença do psicólogo nas instituições é a existência de queixas recorrentes relacionadas à deterioração da saúde. Dentre elas, aquelas referentes à saúde mental ocupam posição de destaque.

As práticas desenvolvidas por esses profissionais nos sindicatos apresentados são bastante diferentes entre si: o psicólogo do sindicato do setor de telecomunicações, que mantém vínculo empregatício com o sindicato e atua no espaço físico do mesmo, faz atividades de acolhimento, orientação e encaminhamentos necessários dos trabalhadores que procuram o departamento de saúde do sindicato. Além disso, ele oferece informações aos usuários, realiza e apóia pesquisas, ministra cursos nas Comissões Internas de Prevenção de Acidentes (Cipas) e opera a seleção de pessoal do próprio sindicato. Já o psicólogo do sindicato dos metalúrgicos, que não é contratado diretamente pelo sindicato, realiza atendimentos psicoterápicos breves aos trabalhadores em seu consultório particular, sendo que o sindicato paga parte ou a totalidade do valor desse serviço para seus associados. Ele também produz laudos técnicos acerca do nexo entre agravos à saúde mental e trabalho.

Nossa análise não exaustiva de sítios de diversos sindicatos brasileiros nos faz concordar com os autores acima acerca do provável ineditismo dessas ações de psicólogos em sindicatos: encontramos nos sítios apenas dois sindicatos (além daqueles em que realizamos nossas atividades) em que há profissionais de saúde mental presentes. Trata-se das seguintes entidades: Sindicato dos Vigilantes do Estado de Minas Gerais, no qual há um Núcleo de Apoio Psicológico que presta apoio e tratamento para vigilantes vítimas ou que enfrentam situações de violência no trabalho, projeto vinculado à PUC-MG; Sindicato dos Bancários de Brasília, que conta com um grupo de apoio psicológico às vítimas de doenças ocupacionais e a trabalhadores com LER/DORT, projeto vinculado à Universidade de Brasília (UnB).

O que esses dados significam? Será que podemos afirmar que vem se configurando, recentemente, um novo campo de atuação para os trabalhadores da saúde mental no meio sindical? Essas questões, certamente, merecem novas investigações. Entendemos que a atividade de grupo por nós desenvolvida no Sindicato dos Bancários de São Paulo, Osasco e Região se dá no interior desse contexto de encontro com o movimento sindical.

\section{Os grupos desenvolvidos no Sindicato dos Bancários de São Paulo, Osasco e Região}

Os grupos, que são realizados desde 2008, acontecem na sede do Sindicato dos Bancários de São Paulo, Osasco e Região, localizada na região central do município de São Paulo. Os objetivos principais do trabalho são os seguintes:

- desenvolver atividade de acolhimento das pessoas com desgaste mental ${ }^{4}$ que procuram o sindicato;

- compreender o processo de adoecimento no interior das trajetórias de vida e trabalho dos participantes, considerando o momento atual de reestruturação produtiva no setor bancário ${ }^{5}$;

- contribuir com a construção de ações individuais e coletivas de enfrentamento.

A proposta de trabalho em grupo é divulgada pelos meios de comunicação disponíveis (jornais do sindicato, murais, boletim virtual etc.) e o público-alvo, que se inscreve de modo voluntário, é composto por trabalhadores bancários (da ativa, afastados do trabalho ou aposentados) que entendam estar vivendo situações de desgaste mental relacionado ao trabalho.

Cada grupo de dez a doze pessoas participa de aproximadamente dez encontros com periodicidade semanal e duração de duas horas. Os encontros são sempre coordenados por dois estudantes do quarto ano do curso de Psicologia da PUC-SP, sob nossa supervisão ${ }^{6}$. Assumimos o compromisso de realizar, ao final do processo, um encontro devolutivo com os

\footnotetext{
${ }^{4}$ Entendemos por desgaste mental a definição de Seligmann-Silva (1994), que afirma que ele se caracteriza por transformações negativas de um estado mental anterior mais satisfatório em direção a um menos satisfatório, por perdas e deformações subjetivas construídas "diacronicamente, ao longo das experiências de vida laboral e extralaboral dos indivíduos" (p. 80).

${ }^{5}$ Esse objetivo dialoga com a “Abordagem Pluridimensional” (LIMA, 2002; LIMA; ASSUNÇÃO; FRANCISCO, 2002), segundo a qual o entendimento da relação entre saúde mental e trabalho exige o levantamento de dados da história de vida, da história laboral do trabalhador e do seu histórico de adoecimento (no caso do estabelecimento do nexo causal, é necessário, ainda que se confrontem esses levantamentos com pesquisas acadêmicas de natureza epidemiológica e/ou estudos de caso efetuados em trabalhadores da categoria profissional em questão).

${ }^{6}$ Participaram dessas atividades as seguintes duplas de alunos: Camila Junqueira Muylaert e Israel Peisino Jr.; Heloisa Barbin de Lucia e Natalia do Bonfim Nascimento; Mariel Martins e Maria Renata Sarubbi; Fernando O. Souza e Renata Marques.
} 
participantes e outro com representantes do sindicato. Além disso, acordamos sobre o sigilo de nomes e instituições e sobre o fornecimento de certificado de participação. Caso o grupo desencadeie questões psicológicas mais graves ou não pertinentes ao projeto, temos como apoio e respaldo a clínica psicológica da PUC-SP, na qual desenvolvemos a "clínica do trabalho", que oferece, dentre outras possibilidades, psicoterapia individual e em grupo para pessoas com transtornos mentais relacionados ao trabalho.

As atividades do grupo são planejadas em reuniões da equipe coordenadora e nas supervisões semanais que realizamos na universidade e variam conforme as especificidades de cada formação grupal. Assim, há grupos que necessitam de uma ênfase em dinâmicas que estimulem a conversa entre os participantes; em outros, a prioridade é constituir um espaço no qual seja possível expressar os sentimentos envolvidos no processo de adoecimento; em outros ainda, cabe centrar o foco na discussão sobre determinado tema etc.

No interior dessa variação, temos algumas constantes nos grupos:

- no primeiro encontro, procedemos à apresentação dos participantes e ao levantamento de suas expectativas com relação ao grupo; estabelecemos os combinados e as regras que nortearão o trabalho (sigilo de nomes e instituições, periodicidade etc.). É importante que, desde esse momento, busquemos constituir um espaço que potencialize as relações entre os participantes e a formação de laços entre eles;

- procuramos avaliar cada atividade com os envolvidos de modo a aprimorar o projeto;

- a cada novo encontro, resgatamos de modo sintético o que foi produzido pelo grupo até aquele momento, o que deixa claro para os participantes a continuidade e o aprofundamento do conteúdo debatido. Essa ação colabora no processo de restabelecimento psicológico dos participantes, pessoas que, em geral, estão passando por experiências de fragmentação e falta de sentido de suas próprias ações;

- no último encontro, fazemos o fechamento do trabalho, a avaliação final e realizamos a devolutiva, síntese articuladora de tudo o que foi realizado pelo grupo. Conferimos com os participantes se o que apreendemos confere com o vivido pelo grupo e combinamos com eles a devolutiva para o sindicato.

Os grupos mostraram-se promissores quanto à possibilidade de compreensão do processo de adoecimento, bem como de identificação de fatores de desgaste mental na categoria bancária. Esses dois movimentos construíram um conhecimento precioso, tanto para os participantes, quanto para o sindicato.

\section{a) Compreendendo o processo de adoecimento}

Nos depoimentos iniciais dos bancários, em geral, conviviam contraditoriamente críticas mordazes às instituições bancárias e a individualização do problema ("o banco é complicado para todo mundo, mas por que eu é que adoeci?”). Os vetores vida e trabalho apareciam pouco articulados em suas falas. Sendo assim, procuramos tecer com eles relações entre as trajetórias de vida e de trabalho, das quais apresentaremos algumas a seguir. Cada uma delas, além de revelar essas relações e trazer dados acerca dos fatores de desgaste mental, destaca um aspecto da problemática vivida pelos trabalhadores.

\section{Algumas histórias}

Houve consentimento dos participantes dos grupos de que as informações relevantes para a compreensão da situação da categoria bancária poderiam ser tornadas públicas, desde que mantido o sigilo de nomes e instituições. Desse modo, omitimos informações que pudessem revelar as identidades dos participantes, bem como trocamos os nomes das pessoas e das instituições envolvidas.

\section{Márcia}

Márcia é graduada, casada e tem filhos, estando afastada do trabalho na época em que participou do grupo. Ingressou em um banco público quando era bastante jovem, através de concurso público, e trabalhou nessa instituição durante 30 anos. Quando se iniciaram seus problemas de saúde, procurou ajuda psicológica e foi encaminhada a diferentes grupos terapêuticos, mas nenhum discutia seu problema. Queixa-se muito da falta de ética envolvida nas práticas dos profissionais de saúde, além da falta de reconhecimento presente nos bancos, visto que, segundo ela, antigamente os funcionários, aos poucos, subiam de cargo e hoje é comum existirem pessoas com 20 anos de idade "mandando" em profissionais com muitos anos de experiência. Nesse cenário, chegou até a ser hospitalizada por cinco dias devido a uma overdose de medicamento para relaxar.

O ápice de seu adoecimento ocorreu um ano antes do afastamento do trabalho, quando teve uma ausência de memória e ficou inconsciente. Segundo ela, essa crise, que a levou à internação, foi ocasionada pela relação de assédio moral exercida por seu chefe. Disse ter "conhecido a pior parte do seu ser, o mais perverso do seu ser", referindo-se ao ódio que passou a sentir do assediador.

\section{Ana Maria}

Ana Maria ingressou como trabalhadora em um banco público há 20 anos e esteve na ativa até a fusão dessa instituição com um banco privado. Em decorrência desse processo, teve uma crise de pânico e saiu de licença. Apresentando sintomas compatíveis com LER/ DORT durante dez anos, perdeu o movimento dos braços. Relatou que o seu superior exigia que fizesse coisas antiéticas, tais como "empurrar" produtos bancários 
para clientes que não precisam deles, competir com antigos amigos para "bater metas" etc.

\section{Gilda}

Gilda iniciou o seu trabalho num banco privado, instituição que posteriormente foi comprada por outro banco privado. Na época em que participou do grupo, estava afastada do trabalho, o que ela atribuiu à relação de humilhação por parte de sua superior. Segundo ela, "no banco a gente aprende muito, até a sofrer". A bancária já passou por diversos tratamentos (cirurgia de ombro, fisioterapia etc.) com vários profissionais, mas sentia dores incessantes nos membros superiores.

A participante estava fazendo curso de informática e encontrava dificuldades para aprender por etapas. Com relação ao trabalho, afirmou: "a carga de responsabilidade, a pressão é tão grande em cima de você que você enlouquece”. Não conseguia dormir, pois o banco "ficava na minha cabeça". "Em um departamento tem mais chefe do que funcionário", "um monte de gerentes”, afirma. Diz-se espiritualista e acredita em Deus, crendo que "as pessoas que me fizeram o mal irão pagar com Deus”.

\section{Jeremias}

Jeremias trabalhava num banco público que foi posteriormente comprado por um banco privado, permanecendo na ativa por 15 anos, a maioria deles exercendo trabalho noturno. À época do grupo, tinha 48 anos e estava aposentado por transtornos mentais.

O rol de diagnósticos que trouxe para o grupo era extenso e contraditório: foi diagnosticado como portador de depressão, de transtorno bipolar, obsessivo-compulsivo, esquizoide e teve como diagnóstico definitivo o de esquizotípico (CID 10 F20). Interessante destacar que, como acontece com a maioria dos trabalhadores, em seu caso também não foi estabelecido o nexo entre os agravos à saúde e o trabalho.

Estava bem adaptado ao trabalho noturno e seus problemas começaram quando foi obrigado a trocar para o turno da manhã. No novo turno, seu trabalho era barulhento, motivo pelo qual desenvolveu perda auditiva. Tem muita raiva, ódio e "vontade de matar o chefe", de quem sofreu inúmeras humilhações. Humilhações repostas pelos peritos do INSS - segundo ele, na "perícia do INSS parece que você é um réu”. Suava e as mãos ficavam geladas quando tinha que passar pela perícia.

\section{Teresa}

Teresa começou a trabalhar em um banco público como gerente, através de concurso, e quando participou do grupo estava afastada do trabalho. Passou por diversas localidades fazendo cursos e sendo transferida de agência. Seu horário de trabalho era de $13 \mathrm{~h}$ às $19 \mathrm{~h}$, mas, como tantos bancários, essa jornada prolongava-se, sendo ela a última a sair do banco. Desenvolveu síndrome do pânico depois de 10 anos na ativa e o estopim foi uma discussão com a chefia. Além do quadro psicológico, tem também problemas osteomusculares.

Relata ter sofrido assédio moral em vários momentos de sua carreira. O clima de perseguição vivido na instituição acabou sendo a lente através da qual ela passou a olhar todas as coisas. Sentia-se perseguida pelo olhar e pelas falas dos colegas. Havia excesso de reuniões para discutir as pendências de serviços, nas quais se sentia tolhida. Para ela, "se alguém vai fazer justiça não vai ser eu, vai ser Deus!”7.

Sempre que chegava ao grupo, dizia-se cansada. A divulgação de casos semelhantes de adoecimento físico e mental relacionado ao trabalho foi um elemento importante em sua recuperação, sendo o grupo importante para ela nesse sentido. Teresa trouxe inúmeras informações sobre o processo de reestruturação produtiva do banco. Na mudança de chefe houve centralização de todas as atividades. Por alegados "motivos de contenção”, caiu do topo da carreira para a lista junior e, ao invés de ensinar, passou a ter que aprender com os novos funcionários. Houve criação de novas normas de progressão na carreira, bem como de novas funções e cargos para evitar promoções e aumento de salários. Foram escolhidas algumas pessoas para assumir os maiores cargos. Após a reformulação, precisaria de seis anos para alcançar o cargo anterior ao rebaixamento.

\section{José Alencar}

José Alencar se mostrou bastante desestruturado, sem noção de tempo e espaço, relatando sofrer de ansiedade, estresse, irritabilidade, fobia e depressão.

Ingressou em um banco público, posteriormente comprado por um banco privado, através de concurso. A fusão trouxe consigo um "clima de perseguição". Relatou ter sido perseguido por um colega de trabalho e, por conta disso, ter ido "parar na psiquiatria". Fazia perícia mês a mês, depois passou a ser trimestral. Segundo ele, o "inferno de Dante" começou em uma determinada agência e continuou quando foi transferido de agência e de cidade. Por "inferno de Dante", referia-se ao assédio moral que sofreu.

Passou por épocas de depressão e tem grande oscilação de humor. O trabalhador referiu-se a uma tentativa de suicídio, evento que vem se tornando frequente na categoria bancária ${ }^{8}$. Desenvolveu também uma série de distúrbios, problemas com relação à sexualidade etc. Sua participação no grupo foi interrompida por uma

\footnotetext{
${ }^{7}$ Há uma espera desses bancários por justiça contra as pessoas perseguidoras e normalmente é uma justiça divina ou pela natureza. Mariana disse sobre isso: "Fiquei aliviada com o câncer linfático do meu chefe. A natureza fez justiça".

${ }^{8}$ Sobre essa temática, veja a dissertação de Santos (2009), que traz dados alarmantes sobre a ocorrência desse fenômeno entre os bancários, relacionando-o com o contexto da nova organização do trabalho, da reestruturação produtiva presenciada pelo setor, enfim, das condições de trabalho contemporâneas nas instituições bancárias.
} 
crise que o levou a mais uma internação em um hospital psiquiátrico.

\section{Gisele}

Gisele tem 43 anos e, quando participou do grupo, acumulava 22 anos de trabalho em um banco privado. Foi afastada por LER/DORT diversas vezes e, na ausência de transformações no processo de trabalho e de tratamento adequado, com o tempo, foi piorando. Contou que teve um "sentimento explosivo" quando teve o carimbo de afastamento do trabalho na carteira, pois "havia ficado marcada" e as "portas se fechariam". Quando o médico do banco escreveu "inapto" para ela, relata ter sido um choque muito grande, pois sabia que isso significaria ir e vir do INSS. Esse episódio de ter recebido "inapto" marcou muito sua vida, sendo sempre citado por ela. Ela desenvolveu um quadro depressivo e fazia tratamento até aquele momento.

No decorrer do grupo, Gisele voltou a trabalhar, mas teve que ser novamente afastada após sentir dores logo nos primeiros dias na ativa. Relatou que é péssimo sentir dor, saber o motivo e ter que continuar por sentir-se impotente, "não poder fazer nada". Ela disse também que a ansiedade influenciava no aumento da dor e que "quando se é pressionado, a dor é pior”. Faltavam 8 anos para ela se aposentar, mas achava que iria ser demitida antes. Deixou de participar do grupo porque voltou ao trabalho.

\section{b) Conhecendo fatores de desgaste mental na categoria bancária}

A organização do trabalho bancário, geradora de competitividade e sobrecarga, foi um elemento fundamental no processo de adoecimento físico e mental desses trabalhadores participantes do grupo. Verificamos a presença de sobrecarga quanto à complexidade das atividades; à exigência da polivalência; às elevadas cargas psicoafetivas (autocontrole emocional exacerbado, exigências de perfeição no desempenho, alto nível de responsabilidade, insegurança quanto à manutenção do emprego e às perspectivas de carreira); aos múltiplos tipos de pressão temporal (prazos, ritmos etc.). Os trabalhadores são submetidos a medo, humilhações, injustiças e até ilegalidades por parte dos bancos, sendo pressionados a agirem contrariamente a seus valores éticos e morais.

Uma questão que se destaca nos depoimentos é o assédio moral $^{9}$, nem sempre havendo, por parte dos bancários, clareza de que esse assédio é responsabilidade da organização do trabalho bancário. Assim, alguns atribuem a violência exclusivamente ao chefe direto, como se as instituições bancárias e suas formas de gestão não fossem as principais responsáveis pela conduta das gerências. Esse assédio se intensifica em tempos de reestruturação produtiva, quando acontece uma espécie de "guerra de todos contra todos", com intensa disputa pelos postos de trabalho que não serão desativados, pela manutenção do emprego.

Quando adoecidos, muitos vivenciam sentimentos de culpa e derrota pelo que ocorreu, o que aumenta o isolamento vivido, visto sentirem vergonha de falar para pessoas próximas sobre o ocorrido, principalmente para suas famílias (situação exacerbada quando o trabalho no banco era motivo de orgulho para os familiares). Sentem desamparo nos atendimentos realizados por profissionais de saúde que não estabelecem o nexo com o trabalho, que desconhecem as razões do sofrimento apresentado e culpabilizam o trabalhador pelo acometimento. Quando afastados do trabalho, seu cotidiano é preenchido por idas e vindas a médicos, fisioterapeutas, psiquiatras etc. e pela frequência às temidas perícias do INSS, nas quais relatam serem submetidos, em geral, a extremo desrespeito. Além disso, têm que provar que estão doentes, mesmo estando sob tratamento, portando exames etc.

O adoecimento coloca os sujeitos em situações de desestruturação psíquica, com falta de perspectiva futura, intenso sofrimento e sentimento de injustiça, humilhação e derrota. Muitos deles não têm perspectivas para o futuro, temem ser demitidos e, quando o são, lutam por sua reintegração ou aposentadoria por invalidez, pois sabem das dificuldades de reingresso no mundo do trabalho. Quando essa volta aconteceu, no caso dos participantes dos grupos, os trabalhadores sofreram preconceito por parte de gestores e colegas de trabalho, reiterando a autoimagem negativa de pessoas que eram avaliadas como excelentes pelo banco e, repentinamente, são vistas pelos gestores e pelos próprios colegas como "fazendo corpo mole", "inventando problema para não trabalhar".

\section{Reflexões sobre os grupos e seus resultados}

O trabalho realizado foi bastante produtivo. Construiu-se um importante espaço de reflexão e discussão, bem como de relatos e troca de experiências que, no decorrer das atividades dos grupos, proporcionaram uma maior compreensão dos participantes acerca do processo de adoecimento e desgaste mental relacionado ao trabalho. Os grupos possibilitaram descobertas individuais e coletivas e, a partir dessas descobertas e da compreensão dos processos ocorridos, tornou-se possível a reflexão e o planejamento de novas estratégias de enfrentamento do desgaste mental.

Os participantes dos grupos puderam, em geral, fortalecer-se em diferentes aspectos no decorrer do trabalho realizado, na medida em que questionaram o atual contexto de seu trabalho, formularam críticas e criaram no-

\footnotetext{
${ }^{9}$ Concordando com Heloani (2005), entendemos por assédio moral "a exposição de trabalhadores a situações vexatórias, constrangedoras e humilhantes durante o exercício de sua função, de forma repetitiva, caracterizando uma atitude desumana, violenta e antiética nas relações de trabalho, assédio este realizado por um ou mais chefes contra seu subordinado" (p. 104), estando esse comportamento diretamente relacionado às formas contemporâneas de gestão do trabalho, que estimulam a hipercompetição entre os trabalhadores.
} 
vos planos de vida. Foi possível observar características comuns entre os participantes, o que possibilitou a troca de experiências e a realização de sínteses de cada encontro. Assim, os participantes puderam, principalmente, perceber que não estão sozinhos na situação de desgaste mental relacionado ao trabalho. Eles ainda conseguiram notar a importância da união entre os que vivem as mesmas situações, tanto para se discutir formas coletivas de protesto, quanto para se pensar em formas individuais de enfrentar tais situações.

Nesse sentido, destacou-se uma atividade que foi desenvolvida com todos os grupos, a "linha do tempo", que consistiu na produção, por parte de cada um dos participantes, de uma retrospectiva dos principais momentos de suas vidas. Essas "linhas do tempo" buscaram colaborar no entendimento do processo de constituição do sofrimento psicológico de cada um dos sujeitos no interior de suas trajetórias de vida e trabalho. As "linhas do tempo", apesar de guardarem diferenças entre si, são semelhantes em muitos aspectos, especialmente naqueles que se referem ao trabalho. Essa semelhança permite que os participantes tomem consciência de que os problemas vivenciados não são meramente individuais, o que colabora com a desconstrução da "ideologia da culpabilização” (LIMA; OLIVEIRA, 1995).

O grupo configurou-se como um espaço de produção de conhecimento acerca da penosidade do trabalho bancário, permitindo o acesso às intrincadas e complexas minúcias vividas no cotidiano laboral em um contexto de aceleradas mudanças organizacionais, tendo em vista a reestruturação produtiva pela qual o setor bancário vem passando.

\section{Referências}

BRESCIANI, L. P. Panorama da reestruturação produtiva. Cadernos de Psicologia Social e do Trabalho, São Paulo, v. 2, n. 1, p. 39-44, 1999.

CHIESA, A. M. et al. As repercussões emocionais das LER/DORT no cotidiano do trabalhador: a invisibilidade ameaçadora. Revista Brasileira Saúde Ocupacional, São Paulo, v. 27, n. 101/102, p. 9-25, set. 2002.

FARINA, A. S.; NEVES, T. F. S. das. Formas de lidar com o desemprego: possibilidades e limites de um projeto de atuação em psicologia social do trabalho. Cadernos de Psicologia Social do Trabalho, São Paulo, v. 10, n. 1, p. 21-36, 2007.

HELOANI, R. Assédio moral: a dignidade violada. Aletheia, Canoas, n. 22, p. 101-108, jul./dez. 2005.

JACKSON FILHO, J. M.; ASSUNÇÃO, A. A. Trabalho em teleatendimento e problemas de saúde. Revista Brasileira de Saúde Ocupacional, São Paulo, v. 31, n. 114, p. 4-6, jul./dez. 2006.

JACQUES, M. G. C.; AMAZARRAY, M. R. Trabalho bancário e saúde mental no paradigma da excelência.
Há um problema que precisamos equacionar melhor na condução do trabalho: a adesão à proposta. Embora tenha havido baixa evasão nos grupos, eles sempre funcionaram com menos participantes do que poderiam. Tendo em vista o bom aproveitamento daqueles que participaram até agora, consideramos que o problema não está nas características essenciais do projeto. Talvez decorra de dificuldades encontradas pelos participantes, pessoas com intenso sofrimento psíquico, de encontrarem energia para se deslocarem, falar de suas dores e novas perspectivas de vida. Outra possibilidade é a de que essa prática, por ser muito recente no sindicato, necessite de tempo para ser estabelecida como rotina na instituição a fim de se constituir como um espaço de acolhimento e de construção de formas de enfrentamento.

Além dos fatores de desgaste mental no trabalho, os grupos também evidenciaram potencialidade e criatividade nas formas de enfrentamento, na resistência constituída no dia a dia de trabalho. Um documento anônimo produzido por uma bancária e trazido para o grupo representa um bom exemplo dessas estratégias - no caso, um modo de denunciar o que se vive no dia a dia de trabalho. O texto se destaca por sua ironia ao convocar pessoas que "gostam de desafios, são empreendedoras e querem construir carreira" para "trabalhar no banco e saber como é viver sem ter qualidade de vida”. Os bancos garantem, segundo o documento:

que você sofrerá com: desrespeito; humilhação; stress; depressão; ansiedade; síndrome de burnout; assédio moral (se tiver sorte, também o assédio sexual); metas abusivas; insônia; hipersonia; úlcera; gastrite e outras ...ites da vida profissional!

Boletim da Saúde, Porto Alegre, v. 20, n. 1, p. 93-105, jan./jun. 2006.

LACAZ, F. A. C. O campo da Saúde do Trabalhador: resgatando conhecimentos e práticas sobre as relações trabalho-saúde. Cadernos de Saúde Pública, Rio de Janeiro, v. 23, n. 4, p. 757-766, abr. 2007.

LIMA, A. B.; OLIVEIRA, F. Abordagem psicossocial da LER: ideologia e culpabilização e grupos de qualidade de vida. In: CODO, W.; ALMEIDA, M. C. (Org.). LER. diagnóstico, tratamento e prevenção. Uma abordagem interdisciplinar. Petrópolis: Vozes. 1995. p. 1236-1259.

LIMA, M. E. A. Violência e reesturação bancária: o caso do Banco do Brasil. Revista da Federação Nacional dos Psicólogos, Belo Horizonte, v. 1, n. 1, p. 27-41, 2000.

. Esboço de uma crítica à especulação no campo da saúde mental e trabalho. In: CODO, W.; JACQUES, M. G. (Org.) Saúde mental e trabalho: leituras.

Petrópolis: Vozes, 2002. p. 50-81.

LIMA, M. E. A.; ASSUNÇÃO, A. A.; FRANCISCO, J. M. S. D. Aprisionado pelos ponteiros de um relógio: o caso de um transtorno mental desencadeado no trabalho. 
In: CODO, W.; JACQUES, M. G. (Org.). Saúde mental e trabalho: leituras. Petrópolis: Vozes, 2002. p. 209-246.

LUCCA, S. R. de; CAMPOS, C. R. Saúde mental e trabalho: uma discussão a partir do estudo de trabalhadores da atividade de teleatendimento. Revista Brasileira de Medicina do Trabalho, São Paulo, v. 8, n. 1, 2010.

MAENO, M. M.; CARMO, C. Saúde do trabalhador no SUS. São Paulo: Hucitec, 2005.

NEVES, M. Y. R. Trabalho docente e saúde mental - a dor e a delícia de ser (tornar-se) professora. 1999. 277 f. Tese (Doutorado em Ciências da Saúde)-Universidade Federal do Rio de Janeiro, Rio de Janeiro, 1999.

ODDONE, E. I. et al. A luta dos trabalhadores pela saúde. São Paulo: Hucitec, 1986.

PAPARELLI, R. Desgaste mental do professor da rede pública de ensino: trabalho sem sentido sob a política de regularização de fluxo escolar. 2009. 184 f. Tese (Doutorado em Psicologia Social)- Instituto de Psicologia, Universidade de São Paulo, São Paulo, 2009.

RAMALHO, C. C. et al. Viver na baia: dimensões psicossociais da saúde e do controle no trabalho de teleatendimento. Cadernos de Psicologia Social do Trabalho, São Paulo, v. 11, n. 1, p. 19-39, jun. 2008. Disponível em: <http://www.revistasusp.sibi. usp.br/scielo.php?script $=$ sci_arttext\&pid $=$ S1516$37172008000100003 \& \operatorname{lng}=\mathrm{pt} \& \mathrm{nrm}=\mathrm{iso} \& \operatorname{lng}=\mathrm{pt}>$. Acesso em: 27 dez. 2010.

SALES, M. M.; SANCHES, R. A. O. Saúde mental e trabalho: a atuação da Psicologia em Sindicatos. In: COLÓQUIO INTERNACIONAL PSICOSSOCIOLOGIA E SOCIOLOGIA CLÍNICA - HOMENAGEM A EUGENE ENRIQUEZ, 13., 2009, Belo Horizonte. Anais... Belo
Horizonte: UFMG, 2009. ISSN 2176-1086. Disponível em: <http:/www.fafich.ufmg.br/coloquioenriquez/ programacao.pdf. > . Acesso em: 01 jun. 2011.

SANTOS, M. A. F. Patologia da solidão: o suicídio de bancários no contexto da nova organização do trabalho, 2009. 223 f. Dissertação (Mestrado em Administração)Universidade de Brasília, Brasília, 2009.

SATO, L. As implicações do conhecimento prático para a vigilância em saúde do trabalhador. Cadernos de Saúde Pública, Rio de Janeiro, v. 12, n. 4, p. 489495, out./dez. 1996.

SATO, L. et al. Atividade em grupo com portadores de LER e achados sobre a dimensão psicossocial. Revista Brasileira de Saúde Ocupacional, São Paulo, v. 21, n. 79, p. 49-62, jul./set., 1993.

SATO, L.; LACAZ, F. A. de C.; BERNARDO, M. H. Psicologia e saúde do trabalhador: práticas e investigações na Saúde Pública de São Paulo. Estudos de psicologia (Natal), Natal, v. 11, n. 3, p. 281-288, set./dez. 2006.

SEGNINI, L. R. P. Reestruturação nos bancos no Brasil: desemprego, subcontratação e intensificação do trabalho. Educação \& Sociedade, Campinas, v. 20, n. 67, p. 183-209, 1999.

SELIGMANN-SILVA, E. Desgaste mental no trabalho dominado. Rio de Janeiro: UFRJ; São Paulo: Cortez, 1994.

VILELA L. V. O.; ASSUNÇÃO A. A. Os mecanismos de controle da atividade no setor de teleatendimento e as queixas de cansaço e esgotamento dos trabalhadores. Cadernos de Saúde Pública, Rio de Janeiro, v. 20, n. 4, p. 1069-1078, jul./ago, 2004. 